\title{
O Sistema Multiportas de Justiça no âmbito da Fazenda Pública em juízo: superando dogmas
}

\author{
Multi-door Courthouse System in the scope of the Public \\ Treasury in Court: overcoming dogmas
}

\author{
Bruno Bastos de Oliveiral \\ Nathália Késsia de Souza Melo ${ }^{2}$
}

\begin{abstract}
RESUMO:
O presente artigo propõe-se a analisar o congestionamento dos tribunais, mais especificamente no âmbito da Fazenda Pública. A inquietude da pesquisa pode ser evidenciada em face do seguinte questionamento - Como resolver a morosidade no âmbito fazendário dentro do Poder Judiciário? Assim, intenciona-se analisar como a supremacia e indisponibilidade do interesse público atrelada com a morosidade do Poder Judiciário tem dificultado a entrega da tutela jurisdicional, sendo objetivos específicos a análise da necessidade de meios adequados de resolução de conflitos e como seria a aplicação do sistema multiportas de justiça. Utiliza-se do método pesquisa bibliográfica e documental e a abordagem qualitativa. Conclui-se pela necessidade de superação de dogmas e a consequente releitura da supremacia e indisponibilidade do interesse público, de forma a inaugurar nova ótica pautada na dignidade da pessoa humana, na qual os interesses públicos e privados deixam de ser contraditórios e se tornam conexos, possibilitando a aplicação do sistema multiportas de justiça nos litígios envolvendo a Fazenda Pública.
\end{abstract}

\section{PALAVRAS-CHAVE:}

Fazenda Pública. Morosidade. Poder Judiciário. Sistema multiportas. Soluções adequadas.

\section{ABSTRACT:}

The present article proposes to analyze the congestion of the courts, more specifically in the scope of the Public Treasury. The restlessness of the research can be evidenced in light of the following questioning - How to solve the slowness in the field of finance within the Judiciary Power? Thus, it intends to analyze how the supremacy and unavailability of the public interest tied to the slowness of the Judiciary Power has made it difficult to delivery the jurisdictional protection, with the specific objectives of the analysis of the necessity of adequate means of conflict resolution and how would the application of the multi-door courthouse system of justice be. The bibliographical and documentary research method and the qualitative approach are used. It concludes on the necessity of overcoming dogmas and the consequential re-reading of the supremacy and unavailability of the public interest, in order to inaugurate a new perspective based on the dignity of the human person, in which public and private interests cease to be

\footnotetext{
${ }^{1}$ Pós-doutorando pela UNIMAR, onde é professor vinculado ao PPGD - Mestrado e Doutorado. Doutor e Mestre em Direito pela UFPB - Universidade Federal da Paraíba. E-mail: bbastos.adv@ gmail.com. Telefone: (83) 991158462.

2 Pós-graduanda em Direito Tributário pelo IBET. E-mail: nathalia.kessia@hotmail.com. Telefone: (83) 987029743.
} 
contradictory and become connected, making the application of the multi-door courthouse system of justice possible in disputes involving the Public Treasury.

\section{KEYWORDS:}

Public Treasury. Slowness. Judiciary Power. Multi-door System. Appropriate Solutions.

\section{INTRODUÇÃO}

Questões das mais complexas nos dias atuais diz respeito à forma de entrega da tutela jurisdicional no Brasil, especialmente no que tange ao alto índice de congestionamento do Poder Judiciário e a consequente morosidade na solução dos conflitos que são levados à julgamento.

Quando se fala na Fazenda Pública, a situação torna-se ainda mais delicada devido as temáticas abordadas e aos princípios norteadores da personificação do Estado, tais como a supremacia e indisponibilidade do interesse público. Ademais, fato é que o Estado está entre os maiores litigantes conforme dados fornecidos pelo Conselho Nacional de Justiça.

Ao mesmo tempo em que o Estado precisa buscar meios de se desenvolver, em especial economicamente, depara-se com um cenário completamente desestimulante ao investidor que cogita iniciar uma atividade econômica em âmbito nacional, vez que a atual realidade brasileira impõe exigências típicas de grande burocratização da Administração Pública por meio do complexo sistema tributário, marcado por elevados índices de litigiosidade. Assim, promove-se um ambiente de injustiça fiscal e consequente déficit de cidadania, nocivo ao desenvolvimento, que poderia resultar do incentivo ao investimento privado.

O próprio Conselho Nacional de Justiça $(\mathrm{CNJ})$ vem atuando de modo a incentivar a escolha por mecanismos alternativos para solução de conflitos, "desafogando" o Judiciário. Estes problemas são especialmente identificados nos litígios de natureza fiscal, seja quando o contribuinte reside no polo passivo ou quando o Estado é o demandado, sabendo-se que não há qualquer mecanismo hábil a aliviar a grande litigiosidade fiscal brasileira contemporaneamente.

Sobre a necessidade de se criar mecanismos alternativos para solução de conflitos, em especial os de natureza tributária, cabe lembrar que o Poder Judiciário está prestes a submergir 
ante o acúmulo de questões a julgar, fato que retarda suas decisões e a efetiva entrega da prestação jurisdicional, ficando o jurisdicionado em situação de delicada insegurança jurídica.

Muitos apontam para o fato de que o sistema tradicional de solução de conflitos está esgotado e precisa urgentemente ser repensado. Exatamente neste ponto que vêm à tona discussões sobre a arbitragem e primordialmente sobre a adoção do procedimento arbitral para solução de litígios de natureza tributária, pois tais litígios, tanto na seara administrativa quanto na judicial, se avolumam e chegam ao patamar de completa ineficácia do sistema.

Neste artigo, serão abordados, de maneira sucinta, o conceito e as principais prerrogativas da Fazenda Pública em Juízo, a viabilidade do sistema multiportas de justiça, bem como as novas interpretações dos dogmas e princípios norteadores do Estado. Por fim, será demonstrado uma possível aplicação do sistema multiportas de justiça no âmbito fazendário e a eficiência que traria a aplicação da justiça aos processos envolvendo a Fazenda Pública.

\section{ASPECTOS GERAIS ACERCA DA FAZENDA PÚBLICA EM JUÍzo E AS PRINCIPAIS PRERROGATIVAS PROCESSUAIS}

Em primeiro lugar, é de extrema importância conceituar a Fazenda Pública em Juízo para que se vislumbre o instituto de uma forma ampla e sirva como base para entender a autocomposição nesta seara.

No dizer Leonardo Carneiro da Cunha ${ }^{3}$ o termo Fazenda Pública em Juízo representa a personificação do Estado abrangendo as pessoas jurídicas de direito público. Em Direito Processual quando se alude a referida expressão apresenta-se como sinônimo do Poder Público em Juízo.

\footnotetext{
${ }^{3}$ CUNHA, Leonardo Carneiro da. A Fazenda Pública em juízo. 14 ed. rev., atual e ampl. Rio de Janeiro: Forense,
} 2017. 
Segundo anota Helly Lopes Meirelles 4 “a Administração Pública, quando ingressa em juízo por qualquer das entidades estatais, por suas autarquias, por suas fundações públicas ou por seus órgãos que tenham capacidade processual, recebe a designação tradicional de Fazenda Pública, porque seu erário é que suporta os encargos patrimoniais da demanda".

Cumpre ressaltar que a expressão Fazenda Pública comumente associada ao termo erário não se resume a este, tendo em vista no âmbito judicial as demandas não versarem exclusivamente sobre a matéria estritamente fiscal ou financeira. Entende-se assim que as pessoas jurídicas de direito público, no âmbito da fazenda pública em juízo, a União, os Estados, os Municípios, o Distrito Federal e suas respectivas autarquias e as fundações públicas, não estando nesse rol as empresas públicas e as sociedades de economia mista, pois revestem-se da natureza de pessoas jurídicas de direito privado.

Em suma, o termo está consolidado no direito público e privado, e é bom salientar que a Fazenda Pública em Juízo não se resume a matéria tributária, abrange em sua totalidade as matérias que tenham como condão o interesse público e cabendo, portanto, esse interesse ser tutelado pela Administração Pública em Juízo.

Tratando-se da capacidade postulatória da Fazenda Pública em Juízo sua representação é feita, em regra, por procuradores judiciais, os quais são titulares de cargos públicos privativos de advogados regularmente inscritos na Ordem dos Advogados do Brasil, não sendo necessária haver procuração a representação do vínculo legal mantido com a Administração Pública e o procurador.

A Fazenda pública se faz presente em juízo pela Advocacia Pública, os membros da advocacia pública são advogados a quem se confere a capacidade postulatória, instituição reconhecida nos arts. 131 e 132 da Constituição da República Federativa do Brasil ${ }^{5}$. Segundo o texto constitucional vigente, o ingresso na advocacia pública dependerá de concurso público e os Procuradores exercerão a representação judicial e consultoria jurídica.

\footnotetext{
${ }^{4}$ MEIRELLES, Hely Lopes. Direito Administrativo Brasileiro. 24. ed. São Paulo: Malheiros, 1998.p. 590.

${ }^{5}$ BRASIL. Constituição da República Federativa do Brasil, de 5 de outubro de 1988. Disponível em: http://www.planalto.gov.br/ccivil_03/Constituicao/Constituiçao.htm. Acesso em: 10 out. 2018.
} 
Nessa ordem de ideias, o código de processo civil em seu art. 182 trata também da capacidade postulatória aduzindo que incumbe à Advocacia Pública defender e promover os interesses públicos da União, dos Estados, do Distrito Federal e dos Municípios, por meio de representação judicial, em todos os âmbitos federativos, das pessoas jurídicas de direito público que integram a administração direta e indireta ${ }^{6}$.

Isto posto, quando o procurador, o advogado público, atua perante o poder judiciário é a Fazenda Pública presente em juízo. Incumbe a ele defender os interesses das pessoas jurídicas de direito público no exercício da atividade jurisdicional.

Sob a máxima aristotélica, o princípio da igualdade, positivado na Constituição Federal no art. 5, caput, ensina que a igualdade não consiste em tratar todos de forma igualitária, mas sim, tratar a todos igualmente, na medida das suas igualdades, e todos os desiguais na medida das suas desigualdades.

Tomando como base este ensinamento notório sobre igualdade, cumpre agora a análise das prerrogativas processuais da Fazenda Pública de modo mais justo. Ademais, Mello ${ }^{7}$ afirma que a lei não deve ser fonte de privilégios ou perseguições, mas instrumento regulador da vida social que necessita tratar equitativamente todos os cidadãos.

De tal sorte, o princípio da igualdade no processo civil, como aduz Cunha ${ }^{8}$ está previsto no art. $7^{\circ}$ do Código de Processo Civil e é complementado pelo texto do art. 139, I, do mesmo código. A igualdade processual assegura a "paridade de armas" e incube-se ao magistrado assegurar a igualdade de tratamento, sendo o princípio do contraditório e ampla defesa intrinsicamente ligado a tal premissa.

Com efeito, as prerrogativas processuais fazendárias têm embasamento constitucional e infraconstitucional e servem para dirimir possíveis desigualdades no procedimento. As regras especiais conferidas à Fazenda Pública, entre as quais destacam-se: a remessa necessária (CPC,

\footnotetext{
${ }^{6}$ BRASIL. Código de Processo Civil, Lei 13.105, de marco de 2015. Disponível em: http://www2.senado.gov.br/bdsf/handle/id/507525. Acesso em: 10 out. 2018.

${ }^{7}$ MELLO, Celso Antônio Bandeira de. Curso de Direito Administrativo. 33. ed. rev. e atual. São Paulo: Malheiros, 2016.

${ }^{8}$ CUNHA, Leonardo Carneiro da. A Fazenda Pública em juízo. 14 ed. rev., atual e ampl. Rio de Janeiro: Forense, 2017
} 
art.496), prazos diferenciados com intimação pessoal (CPC, art.183), competência territorial (CPC, art. 1.048). A Fazenda Pública em juízo significa a defesa do erário público.

Por tais razões, a fazenda pública faz jus as prerrogativas apresentadas pois, tutela o próprio interesse público em detrimento do particular, ostentando assim condição diferenciada das demais pessoas jurídicas e físicas de direito privado. As prerrogativas processuais não se resumem a simples privilégios são condições necessárias que viabilizam o exercício do interesse público em juízo, vez que privilégios podem ser, muitas vezes, odiosos, o que não se configura na presente análise.

\section{SISTEMA MULTIPORTAS E A SOLUÇÃO PACÍFICA DOS CONFLITOS: MAIS QUE UMA POSSIBILIDADE, UMA NECESSIDADE}

Afim de alcançar a solução pacífica dos conflitos submetidos ao Judiciário, mais especificamente no âmbito dos processos em que figura como parte a Fazenda Pública, faz-se necessário entender o a dogmática do sistema multiportas de justiça. Desde já afirma-se que a busca por métodos mais adequados de solução de conflitos se mostra atualmente não como mera possibilidade, mas sim como única alternativa viável de enfrentamento da crise de efetividade que abala a entrega da tutela jurisdicional. Conforme aduz Nancy Andrighi e Gláucia Falsarella Foley ${ }^{9}$ :

Para o sistema operar com eficiência, é preciso que as instâncias judiciárias, em complementaridade à prestação jurisdicional, implementem um sistema de múltiplas portas, apto a oferecer meios de resolução de conflitos voltados à construção do consenso -dentre eles, a mediação.

Diferentemente "dos meios alternativos de resolução de conflitos" o sistema multiportas de justiça não entende que os meios, mediação, conciliação, negociação e arbitragem, não são "alternativos", mas sim "adequados". Ou seja, não se buscaria a melhor alternativa, mas sim o método adequado que possibilitasse a efetiva resolução do conflito.

\footnotetext{
${ }^{9}$ ANDRIGHI, Nancy; FOLEY, Gláucia Falsarella. Sistema multiportas: o Judiciário e o Consenso. Folha de São Paulo, São Paulo, jun.2008. Disponível em: http://www.justica.gov.br/central-de-conteudo/reformadojudiciario/artigos/sistema-multiportas.pdf . Acesso em: 31 de maio de 2018, p. 1.
} 
Nessa ordem de ideias, Cunha ${ }^{10}$ em sua consagrada doutrina sobre a Fazenda pública em Juízo aduz que:

Para cada tipo de controvérsia, seria adequada uma forma de solução, de modo que há casos em que a melhor solução há de ser obtida pela mediação, enquanto outros, pela conciliação, outros, pela arbitragem e, os que se resolveriam pela decisão do juiz estatal.

Com efeito, a expressão multiportas decorre de uma metáfora: seria como se houvesse, no átrio do fórum, várias portas; a depender do problema apresentado, as partes seriam encaminhadas para a porta da mediação, ou da conciliação, ou da arbitragem, ou da própria justiça estatal.

No Brasil a utilização do sistema multiportas de justiça ainda é mínima se comparada com os Estados Unidos, é o que se denomina de sistema multi-door courthouse, o qual tem o objetivo fornecer o melhor método para a resolução de um dado conflito.

Por esse prisma, o cidadão teria a disposição várias alternativas para solucionar um conflito. O objetivo do sistema multiportas é buscar formas de solução de conflitos que substituam o tradicional sistema judicial de solução de litígios ou que essas novas formas possam coexistir com a tutela jurisdicional estatal ${ }^{11}$.

No presente artigo, o sistema multiportas de justiça, idealizado nos Estados Unidos, vislumbra-se como uma solução pacífica dos conflitos necessária para auxiliar a atividade jurisdicional estatal a encontrar o meio mais adequado de solução do litigio.

O congestionamento no Poder Judiciário não é novidade. Segundo Maus ${ }^{12}$ : "a sociedade está órfã e o Judiciário é seu superego". Com efeito, este congestionamento é fruto de diversos problemas como falta de servidores e a litigância excessiva, isto têm gerado uma justiça tardia e ineficaz.

\footnotetext{
${ }^{10}$ CUNHA, Leonardo Carneiro da. A Fazenda Pública em juízo. 14 ed. rev., atual e ampl. Rio de Janeiro: Forense, 2017, p. 639.

11 BRANDÃO, Fernanda Holanda de Vasconcelos. Advocacia negocial: promoção do acesso à justiça pela desjudicialização dos conflitos. João Pessoa: A União, 2014.

12 MAUS, Ingeborg. Judiciário como superego da sociedade: o papel da atividade jurisprudencial na "sociedade órfã” - São Paulo: Revista Novos Estudos CEBRAP, 2002.p.186.
} 
Segundo o Conselho Nacional de Justiça no projeto “Justiça em Números de 2017” a taxa de congestionamento mede o percentual de processos que ficaram represados sem solução, comparativamente ao total tramitado no período de um ano. Quanto maior o índice, maior a dificuldade do tribunal em lidar com seu estoque de processos. A taxa de congestionamento líquida, por sua vez, é calculada retirando do acervo os processos suspensos ou sobrestados ou em arquivo provisório. ${ }^{13}$

O relatório dos "100 Maiores Litigantes" elaborado pelo Conselho Nacional de Justiça busca identificar quais são esses principais demandantes e o que pode ser feito para reduzir a litigância excessiva no Brasil ${ }^{14}$.

Como abordado anteriormente, a Fazenda Pública em juízo corresponde as pessoas jurídicas de direito público a União, os Estados, os Municípios, o Distrito Federal e suas respectivas autarquias e as fundações públicas. Estes entes estão entre os dez maiores litigantes.

Os gráficos elaborados pelo Conselho Nacional de Justiça são cristalinos e demonstram a complicadíssima realidade do Poder Judiciário Brasileiro. Sãos mais de setenta milhões de processos pendentes e mais de vinte milhões de novas demandas. Como demonstrado, a justiça estadual possui setenta e cinco por cento de congestionamento enquanto a justiça federal setenta e quatro por cento. E a Fazenda pública, no âmbito federal, estadual e municipal, estão no topo da tabela dos maiores litigantes.

Em razão dessa realidade, buscar meios adequados para a resolução dos litígios tem se tornado uma tarefa imprescindível, não apenas para resolver as demandas novas, mas como também as demandas já existentes. No âmbito fazendário, além do volume das demandas, o engessamento dos princípios da Supremacia e Indisponibilidade do interesse público tem tornado essa tarefa ainda mais delicada.

\footnotetext{
${ }^{13}$ BRASIL. Conselho Nacional de Justiça. Justiça em Números 2017: ano-base 2016. Brasília. 2017.

${ }^{14}$ BRASIL. Conselho Nacional de Justiça. Os 100 Maiores Litigantes. Brasília. 2011.
} 


\section{SUPREMACIA E INDISPONIBILIDADE DO INTERESSE PÚBLICO: A SUPERAÇÃO DE DOGMAS}

Não é uníssono o conceito de interesse público, no entanto é predominantemente utilizado para exprimir o interesse de proveito social ou geral, o interesse da coletividade considerada em seu todo, segundo afirma Mazzilli1 ${ }^{15}$.

Conforme Melo ${ }^{16}$ em sua obra Curso de Direito Administrativo conceitua o interesse público como: “o interesse resultante do conjunto dos interesses que os indivíduos pessoalmente têm quando considerados em sua qualidade de membros da sociedade e pelo simples fato de o serem". Note-se que o interesse público está intrinsicamente atrelado a coletividade que vive em sociedade e busca o bem comum em detrimento do interesse do particular.

Interessante se faz notar que o interesse público consiste na contraposição do interesse do Estado ao interesse do indivíduo, enquanto este consiste na contraposição entre indivíduos em seu inter-relacionamento, no dizer de Mazzilli ${ }^{17}$.

Essas concepções de interesse público são fruto da evolução histórica que no final do século XIX e começo do século XX reconfiguraram o que se entendia por interesse público e bem comum enquadrando-as em uma Espécie de Estado Social de Direito.

Por esse prisma, embora possa haver um interesse público incompatível com um determinado interesse individual, é inconcebível que haja um interesse público discordante dos interesses de cada um dos membros da sociedade. Percebe-se, destarte, uma relação indissociável entre o interesse público e os interesses individuais ${ }^{18}$.

\footnotetext{
${ }^{15}$ MAZZILLI, Hugo Nigro. A defesa dos interesses difusos em juízo: meio ambiente, consumidor, patrimônio cultural, patrimônio público e outros interesses - 17.ed. rev., ampl. e atual. - São Paulo: Saraiva, 2004.

${ }^{16}$ MELLO, Celso Antônio Bandeira de. Curso de Direito Administrativo. 33. ed. rev. e atual. São Paulo: Malheiros, 2016, p. 62.

17 MAZZILLI, Hugo Nigro. A defesa dos interesses difusos em juízo: meio ambiente, consumidor, patrimônio cultural, patrimônio público e outros interesses - 17.ed. rev., ampl. e atual. - São Paulo: Saraiva, 2004.

${ }^{18}$ MELLO, Celso Antônio Bandeira de. Curso de Direito Administrativo. 33. ed. rev. e atual. São Paulo: Malheiros, 2016.
} 
Situados entre o interesse público e o interesse individual se encontra os interesses transindividuais. Segundo Cappelleti apud Mazzilli ${ }^{19}$ :

São interesses que excedem o âmbito estritamente individual, mas não chegam propriamente a constituir interesse público. São os compartilhados por grupos, classes ou categorias de pessoa e estão em posição intermediária entre o público e o privado.

É de clareza ímpar que a noção de interesse público é muito mais abrangente do que, habitualmente, ser o conflito do particular contra desvios de uma conduta estatal e é muito mais abrangente do que limitar o interesse público ser o interesse exclusivamente do Estado. Os interesses públicos correspondem à dimensão pública dos interesses individuais e como uma pessoa jurídica que existe e convive no universo jurídico possui interesses que lhe são particulares, individuais, os quais não se confundem com interesse público. Em sua obra Curso de Direito Administrativo, Mello ${ }^{20}$ faz uma fundada observação:

Esta distinção a que se acaba de aludir, entre interesses públicos propriamente ditos isto é, interesses primários do Estado - e interesses secundários, é de trânsito corrente e moente na doutrina italiana, e a um ponto tal que, hoje, poucos doutrinadores daquele país se ocupam em explicá-lo.

Em suma, o interesse público abrange os interesses individuais e os transindividuais. A sociedade é norteada pelo interesse público, entretanto o este interesse é formado por uma coletividade de interesses individuais e nem sempre estão em polos contrários. Os interesses individuais no âmbito fazendário, por causa das temáticas abordadas, acabam refletindo os anseios sociais que estão constitucionalmente resguardados pela Constituição.

O Direito deixou de ser apenas o instrumento de garantia dos direitos do indivíduo e passou a ser visto como meio para a consecução da justiça social, do bem comum, do bem-estar coletivo $^{21}$. Em verdade, ao se organizar em sociedade os indivíduos forneceram ao Estado a função basilar de zelar pelo interesse da coletividade. É através desta função que se manifesta a supremacia do interesse público.

O princípio da Supremacia do interesse público, mesmo não estando previsto expressamente na Constituição de 1988, é princípio geral do Direito inerente a qualquer

\footnotetext{
${ }^{19}$ MAZZILLI, Hugo Nigro. A defesa dos interesses difusos em juízo: meio ambiente, consumidor, patrimônio cultural, patrimônio público e outros interesses - 17.ed. rev., ampl. e atual. - São Paulo: Saraiva, 2004, p. 48.

${ }^{20}$ MELLO, Celso Antônio Bandeira de. Curso de Direito Administrativo. 33. ed. rev. e atual. São Paulo: Malheiros, 2016, p. 66.

${ }^{21}$ DI PIETRO, Maria Sylvia Zanella. Direito Administrativo. 21 ed. São Paulo: Atlas, 2008, p. 64.
} 
sociedade sendo sua a própria condição de existência da mesma. Considerados por muitos doutrinadores um supraprincípio é o responsável por ponderar as atividades administrativas, sejam em juízo ou não, a fim de preservar a tutela dos interesses públicos. Na visão de Gustavo Barchet $^{22}$ :

A própria razão de existir da Administração é a busca dos interesses públicos, e para cumprir a contento sua missão é necessário assegurar que esses interesses, porque pertinentes a toda coletividade, prevaleçam sobre os interesses privados de seus membros.

Não resta dúvida que, por a Administração atuar pelos interesses mais básicos e relevantes do corpo social deve gozar de superioridade perante os administrados a fim de assegurar a prevalência desses interesses.

É certo que a supremacia do interesse público é basilar para o Estado Democrático de Direito. Ao elevar o interesse público em detrimento do particular a Constituição da República federativa do Brasil buscou a efetivação da atividade estatal. Por outro prisma, a supremacia do interesse público não pode ser a responsável por impedir a entrega da tutela jurisdicional no âmbito fazendário. Este princípio deve ser sempre observado, mas não pode ser o empecilho para que se discuta meios adequados de resolução de litígios.

Assim como, o princípio da Supremacia do interesse público o princípio ora abordado não está explícito no art. 37 da Constituição da República Federativa do Brasil, no qual elenca os princípios que regem a administração pública, é, pois, um princípio implícito, mas não menos importante. Como anteriormente afirmado, juntamente com o princípio da Supremacia do interesse público é considerado um supraprincípio do regime jurídico-administrativo.

Decorre do princípio da indisponibilidade do interesse público o poder-dever de agir da administração, enquanto o particular tem a faculdade em seus interesses para que possa escolher o que melhor lhe aprouver a Administração Pública está em situação diametralmente oposta, pois sempre que a ordem jurídica confere a administração um poder faz para que determinado interesse público seja satisfeito ${ }^{23}$.

\footnotetext{
${ }^{22}$ BARCHET, Gustavo. Direito Administrativo. 2 ed. Rio de Janeiro: Elsevier, 2011, p. 54.

${ }^{23}$ BARCHET, Gustavo. Direito Administrativo. 2 ed. Rio de Janeiro: Elsevier, 2011.
} 
Isto posto, a administração dos bens e dos interesses públicos não estão entregues à livre disposição da vontade do administrador, o dever de curá-los é nos termos que dispõe a ordem legal, não possuindo, portanto, disponibilidade sobre os interesses públicos. A indisponibilidade do interesse público embora seja um princípio norteador da administração pública, na visão moderna, não impossibilita que tal princípio seja relativizado. O Direito está em constante movimento e a crise dos paradigmas do Direito Administrativo não constitui algo novo. As transformações que passa o Estado agravam o descompasso entre as velhas categorias e as reais necessidades e expectativas das sociedades contemporâneas em relação a Administração Pública. Nesse diapasão, surge a constitucionalização do direito administrativo que pauta a atuação do ente na dignidade da pessoa humana e o situa acima do conceito do interesse público ${ }^{24}$.

A Carta de outubro trouxe com fundamento do Estado Democrático de Direito a dignidade da pessoa humana. Esse paradigma norteia todo o ordenamento jurídico e Fazenda Pública em Juízo não seria de forma diversa.

As constantes mudanças que enfrenta a sociedade, em especial no âmbito do Poder Judiciário, devem ser observadas para se buscar a efetiva entrega da tutela jurisdicional.

Por esse prisma, ao se desconstruir a indisponibilidade e supremacia do interesse público, reconstruindo sob a ótica constitucional da dignidade da pessoa humana permite-se uma maior abertura para a aplicação de meios adequados a solução dos litígios enfrentados pela Administração Pública em sentido amplo, tal como o sistema multiportas de justiça.

O princípio da supremacia do interesse público sobre o particular como uma sistemática constitucional cidadã, comprometida com a proteção e promoção dos direitos individuais de maneira ponderada e compatível com a realização das necessidades e aspirações da coletividade como um todo. Devendo, portanto, a Administração Pública, em todas as suas esferas, pautar-se na proporcionalidade ${ }^{25}$.

\footnotetext{
${ }^{24}$ BINENBOJM, Gustavo. Da supremacia do interesse público ao dever de proporcionalidade: um novo paradigma para o direito administrativo. Revista de Direito Administrativo, Rio de Janeiro, v. 239, p. 1-32, jan. 2005. Disponível em: http://bibliotecadigital.fgv.br/ojs/index.php/rda/article/view/43855. Acesso em: 21 de maio de 2018.

${ }^{25}$ BINENBOJM, Gustavo. Da supremacia do interesse público ao dever de proporcionalidade: um novo paradigma para o direito administrativo. Revista de Direito Administrativo, Rio de Janeiro, v. 239, p. 1-32, jan. 2005.
} 
Vale-se destacar que a proporcionalidade acima referida não busca excluir a supremacia do interesse público, afinal este é indispensável ao Estado de Bem-estar Social, contudo, ao se utilizar a proporcionalidade prestigia-se, dependendo do caso, tanto o interesse público como o interesse particular, pois ambos estão intrinsicamente conectados.

O conteúdo constitucional descrito presta-se também com fundamento a negar a colisão entre interesses públicos e privados. Verifica-se que ambas se encontram enraizadas na Constituição havendo entre eles uma conexão e não uma contradição.

Isto posto, vislumbra-se uma superação de dogmas a fim de propiciar uma constitucionalização da Administração Pública e a valorização do indivíduo através da dignidade da pessoa humana. A utilização da proporcionalidade em detrimento da supremacia acarreta que seja observada qual interesse, no caso concreto, deve ser privilegiado. Assemelhase a isso a utilização da ponderação, na qual ambos os princípios têm o mesmo peso, devendose observar qual melhor se encaixa ao caso concreto. No âmbito fazendário, a partir da superação dos dogmas e da conexão existente entre interesse público e privado, deve-se buscar qual interesse será tutelado e qual o meio mais adequado para solução pacífica do litigio.

\section{APLICAÇÃO DO SISTEMA MULTIPORTAS NO ÂMBITO DA FAZENDA PÚBLICA EM JUÍzO}

A Constituição Federal de 1988 em seu art. 5o, XXXV, afirma que a lei não excluirá da apreciação do Poder Judiciário lesão ou ameaça a direito. Entretanto, conforme amplamente demonstrado, o congestionamento judicial tem impossibilitado a entrega da tutela jurisdicional, ou em outros casos é feita tardiamente. Importante salientar que em ambos os casos acabasse ocorrendo injustiças. Soma-se a isto a questão da Fazenda pública está entre os dez maiores litigantes.

Disponível em: http://bibliotecadigital.fgv.br/ojs/index.php/rda/article/view/43855. Acesso em: 21 de maio de 2018. 
O sistema multiportas de justiça surge como uma alternativa para a resolução, principalmente dos processos pendentes, dos litígios. No âmbito fazendário, para aplicação desse sistema, é imprescindível a visão moderna dos institutos da indisponibilidade e supremacia do interesse público.

A aplicação do sistema multiportas de justiça na Fazenda pública pode ser feita de duas formas: por meios dos advogados e procuradores ou com a implementação de uma junta especializada na análise de qual porta deve ser aberta.

No primeiro caso os advogados públicos, pois está em análise a Fazenda Pública, podem buscar e propor o meio adequado de solução do conflito, seja de forma preventiva ou já no curso do processo. Ao possuir a capacidade postulatória fazendária os procuradores possuem as mesmas prerrogativas dos advogados privados, podendo se utilizar da advocacia negocial, mediação, conciliação, arbitragem e da tutela estatal. Sempre levando em consideração quais desses meios será mais efetivo para resolver de maneira célere e pacifica o conflito em tela.

Por sua vez a implementação da junta especializada serviria como uma análise prévia dos fatos, tal como a utilizada na Corte Superior do Distrito de Columbia, Estados Unidos. Buscando-se um diagnóstico do litigio e ofereceriam o meio mais adequado para solucionar o conflito. Essa junta especializada, dentro do próprio Poder Judiciário, não seria responsável por dizer o Direito, mas sim, faria uma análise a partir do que lhes foi apresentado, emitindo parecer sugerindo através do sistema multiportas de justiça qual o caminho mais adequado.

\section{CONCLUSÃO}

A cultura excessivamente adversarial e os problemas existentes em um sistema pautado nessa cultura culminaram no congestionamento do Poder Judiciário. Dentre os litígios destacam-se aqueles que possuem a fazenda pública como ré ou autora. Este cenário resultou em um engessamento judicial. 
A superação dos dogmas inaugura uma nova ótica pautada na dignidade da pessoa humana, fundamento da República Federativa do Brasil, demonstra uma conexão, e não contradição, entre os interesses públicos e privados. Permitindo assim que conflitos na seara fazendária deixem de ser adversariais e passem a ser mais cooperativos.

Restou assinalado que se deve buscar mecanismos adequados de resolução de conflitos ante a inoperância dos meios tradicionais. Os problemas reais no monopólio do Poder Judiciário exigem dos pesquisadores uma investigação madura para superar o atual estado das coisas, com vistas a propor mudanças que gerem resultados positivos, até porque a incapacidade de o Poder Judiciário se apresentar como instancia efetiva de solução de conflitos afeta decisivamente o desenvolvimento econômico e social do país.

É preciso encontrar mecanismos adequados de solução de conflitos, especialmente naqueles em que a Fazenda Pública figura em juízo. Dessa forma, concluímos que a solução reside essencialmente na concepção e implementação de novos mecanismos de realização de justiça, sem que isso signifique anular o significante e constitucional papel do Poder Judiciário.

O princípio constitucional da eficiência na Administração Pública ao mesmo tempo pressupõe a modernização estatal. A regulamentação e efetivação de meios adequados para solução de litígios está ligado à análise de como o Estado vem mudando e como a implementação desses meios vai ao encontro da necessidade de modernização dos instrumentos estatais, em especial dos mecanismos de solução de controvérsias.

Nesse sentido, corroborado pelo fato de que não há na $\mathrm{CF} / 88$ qualquer indicativo da existência de monopólio da função jurisdicional em favor do Poder Judiciário, negar a possibilidade de utilização de mecanismos que se mostrem mais adequados e eficazes para solução de conflitos envolvendo a Administração Pública seria afrontar a própria essência do que representaria o verdadeiro interesse público.

O Sistema Multiportas de Justiça, através da aplicação dos meios adequados a resolução pacíficas dos litígios, surge como uma saída para congestionamento do Poder Judiciário, em especial aos litígios pendentes. Seria como se houvesse, no átrio do fórum, várias portas e a depender do problema apresentado, as partes seriam encaminhadas para a porta que mais se adequasse e possibilitasse a resolução pacífica. 
O contexto do Estado Democrático cooperativo e eficiente pressupõe a adoção de métodos adequados para solução de conflitos de natureza tributária, resultando, assim, na efetivação de um processo de modernização estatal, nos limites da lei e amparadas na ideia de interesse público.

\section{REFERÊNCIAS}

ANDRIGHI, Nancy; FOLEY, Gláucia Falsarella. Sistema multiportas: o Judiciário e o Consenso. Folha de São Paulo, São Paulo, jun.2008. Disponível em: http://www.justica.gov.br/central-de-conteudo/reforma-dojudiciario/artigos/sistemamultiportas.pdf. Acesso em: 31 mai. 2018.

BARCHET, Gustavo. Direito Administrativo. 2 ed. Rio de Janeiro: Elsevier, 2011.

BINENBOJM, Gustavo. Da supremacia do interesse público ao dever de proporcionalidade: um novo paradigma para o direito administrativo. Revista de Direito Administrativo, Rio de Janeiro, v. 239, p. 1-32, jan. 2005. Disponível em: http://bibliotecadigital.fgv.br/ojs/index.php/rda/article/view/43855. Acesso em: 21 mai. 2018.

BRANDÃO, Fernanda Holanda de Vasconcelos. Advocacia negocial: promoção do acesso à justiça pela desjudicialização dos conflitos - João Pessoa: A União, 2014.

BRASIL. Código Civil, Lei 10.406, de 10 de janeiro de 2002. 1a edição. São Paulo: Revista dos Tribunais, 2002.

BRASIL. Código de Processo Civil, Lei 13.105, de marco de 2015. Disponível em: http://www2.senado.gov.br/bdsf/handle/id/507525. Acesso em: 10 out. 2018.

BRASIL. Constituição da República Federativa do Brasil, de 5 de outubro de 1988. Disponível em: http://www.planalto.gov.br/ccivil_03/Constituicao/Constituiçao.htm. Acesso em: 10 out. 2018.

BRASIL. Conselho Nacional de Justiça. Justiça em Números 2017: ano-base 2016. Brasília. 2017.

BRASIL. Conselho Nacional de Justiça. Os 100 Maiores Litigantes. Brasília. 2011.

CUNHA, Leonardo Carneiro da. A Fazenda Pública em juízo. 14 ed. rev., atual e ampl. Rio de Janeiro: Forense, 2017. 
DI PIETRO, Maria Sylvia Zanella. Direito Administrativo. 21 ed. São Paulo: Atlas, 2008.

MAUS, Ingeborg. Judiciário como superego da sociedade: o papel da atividade jurisprudencial na "sociedade órfã". São Paulo: Revista Novos Estudos CEBRAP, 2002.

MAZZILLI, Hugo Nigro. A defesa dos interesses difusos em juízo: meio ambiente, consumidor, patrimônio cultural, patrimônio público e outros interesses - 17.ed. rev., ampl. e atual. - São Paulo: Saraiva, 2004.

MEIRELLES, Hely Lopes. Direito Administrativo Brasileiro. 24. ed. São Paulo: Malheiros, 1998.

MELLO, Celso Antônio Bandeira de. Curso de Direito Administrativo. 33. ed. rev. e atual. São Paulo: Malheiros, 2016.

Submetido em: 28/06/2019

Aceito em: 20/10/2019 